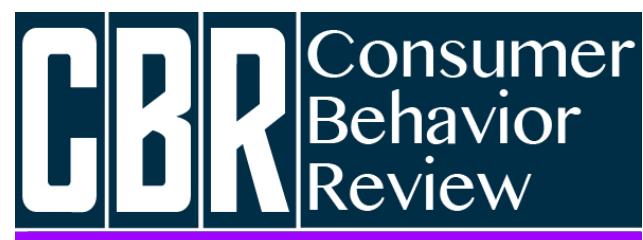

Revista Comportamento do Consumidor
Pinto, M. R., Batinga, G. L., Almeida, G. T., \& Ássimos, B. M. (2020). Histórias, Narrativas de Vida e Estudos de Consumo: Uma aproximação viável? Consumer Behavior Review, 4(3), 261-271.
ISSN: 2526-7884

Editor: Prof. Dr. Marconi Freitas da Costa Journal's e-mail: cbr@ufpe.br
Evaluation: Double blind review

Received: March 31, 2020

Accepted: August 21, 2020

\title{
HISTÓRIAS, NARRATIVAS DE VIDA E ESTUDOS DE CONSUMO: UMA APROXIMAÇÃO VIÁVEL?
}

Stories, Life Narratives and Consumer Studies: a viable approach?

Marcelo de Rezende Pinto ${ }^{1}$

ORCID: http://orcid.org/0000-0002-3251-2460

E-mail: marcrez@pucminas.br

Georgiana Luna Batinga ${ }^{2}$

ORCID: http://orcid.org/0000-0002-1807-9824

E-mail: georgiana.luna@ufms.br

Gustavo Tomaz de Almeida ${ }^{3}$

ORCID: http://orcid.org/0000-0001-6321-168X

E-mail: gustavo.almeida@uemg.br

Bruno Medeiros Ássinos ${ }^{1}$

ORCID: http://0000-0003-1206-6376

E-mail: bruno.assimos@gmail.com

\footnotetext{
${ }^{1}$ Pontifícia Universidade Católica de Minas Gerais, Belo Horizonte, Brasil

${ }^{2}$ Universidade Federal de Mato Grosso do Sul, Campo Grande, Brasil

${ }^{3}$ Universidade Estadual de Minas Gerais, Belo Horizonte, Brasil
}

\section{Resumo \\ 0 consumo na sociedade atual pode ser considerado um fenômeno que atravessa diversos campos de estudo e tangencia diferentes perspectivas de análise, oferecendo}

\begin{abstract}
Consumption in today's society can be considered a phenomenon that crosses several fields of study and touches different perspectives of analysis, offering a wide range
\end{abstract}


uma ampla gama de interpretações, por isso é interessante refletir sobre aproximações com outros campos. Essa percepção oportunizou a elaboração desse trabalho, que tem como objetivo discutir como a abordagem teóricometodológica de histórias e narrativas de vida pode contribuir para o entendimento do consumo como uma prática da vida cotidiana, como um fenômeno amplo, multifacetado, com múltiplos sentidos e vozes. Dessa forma, a condução desse estudo aponta para os diálogos e contribuições possíveis entre o consumo na perspectiva social e culturalmente construída e a abordagem histórias e narrativas de vida. Foram observados pontos de aderência entre a literatura consultada, relacionando-os com os processos intersubjetivos de consumidores baseados nas vivências compartilhadas, que, consensualmente, oferecem sentido ao mundo, comum aos dois campos.

Palavras-chave: Consumo, Narrativas de Vidas, Histórias de Vidas. of interpretations, so it is interesting to reflect on approximations with other fields. This perception made it possible to elaborate this work, which aims to discuss how the theoretical-methodological approach to life stories and narratives can contribute to the understanding of consumption as a practice of everyday life, as a broad, multifaceted phenomenon, with multiple meanings and voices. Thus, the conduct of this study points to the possible dialogues and contributions between consumption in the socially and culturally constructed perspective and the approach to life stories and narratives. Adherence points were observed among the consulted literature, relating them to the intersubjective processes of consumers based on shared experiences, which consensually offer meaning to the world, common to both fields.

Keywords: Consumption, Narratives of Lives, Life Stories.

This work is licensed under a Creative Commons Attribution 4.0 International License.

\section{INTRODUÇÃO}

Pode-se dizer que até bem pouco tempo atrás o consumo não se constituía um campo sistemático, concreto e independente de estudos. Os trabalhos existentes estavam extensamente espalhados em diferentes áreas de pesquisa. No comportamento do consumidor, desde a década de 1950, percebe-se um esforço para se construir um corpo de conhecimento sobre essa temática, ainda que seja possível verificar uma tendência de pulverização das abordagens (Macinnis \& Folkes, 2010). Além disso, muitos dos trabalhos desenvolvidos pouco dialogavam entre si, visto que os campos do design, da economia, da comunicação, dos estudos históricos, da psicologia, da sociologia, da antropologia, entre outros utilizavam referenciais teóricos distintos, métodos de pesquisa específicos e havia pouco interesse por parte dos pesquisadores em empreender conversações entre eles (Lima, 2010). É nessa perspectiva que o consumo na sociedade atual pode ser considerado um fenômeno que atravessa diversos campos de estudo (McCracken, 2003; Desjeux, 2011), tangencia diferentes perspectivas de análise e oferece uma ampla gama de interpretações (Belk, 1995).

Em outras palavras, é um fenômeno com múltiplas vozes. Contudo, o que parece fazer sentido é que, nas últimas duas décadas, houve uma guinada no contexto das Ciências Sociais no sentido de examinar o consumo como algo ordinário, cotidiano, que faz parte da "vida vivida", das pessoas em seu "ambiente" do dia a dia, sem necessariamente julgá-lo como inerentemente ruim e causador de todas as mazelas da sociedade atual (Paterson, 2006). Como enfatiza Desjeux (2011), o consumo ganha um contorno interessante como indicador da vida cotidiana, bem como se alinha a outras questões para se entender as construções identitárias, problemas políticos, dos modos de vida e das estratificações sociais. Ou seja, parece ter todos os pontos para compor um tema ao mesmo tempo leve, mas também carregado de sentidos, implicações e complexidade.

No campo do Marketing, até a década de 1980, sobressaia no campo do comportamento do consumidor (nome que já denomina a posição do campo, eminentemente behaviorista) (Rocha, 2002), estudos com base positivista e com viés quantitativista, na qual o consumo era entendido como fenômeno essencialmente individual e possível de ser entendido por meio de modelos descritivos e 
prescritivos. Porém, Belk (1995) argumenta que a emergência de uma "nova" concepção da pesquisa do consumidor teve início a partir de meados da década de 1980 e ganhou força nos fóruns internacionais do campo nos anos de 1990. Belk (1995) ressalta que a "nova" perspectiva parte da premissa de que os consumidores não são autômatos que recebem, passiva e obedientemente as informações produzidas pelas organizações e maximizam suas satisfações por meio de escolhas orientadas simplesmente pelo custo-benefício, mas sim que os seres humanos são conectados socialmente e são participantes de múltiplas interações culturais.

Frente à posição deflagrada pelas Ciências Sociais no tocante à ampliação do conceito de consumo como algo rotineiro e ordinário, atrelada à constatação de que há no campo da pesquisa do consumidor um "arejamento" para legitimar novas perspectivas de análise e de entendimento desse fenômeno é que se adere à proposta desse ensaio. Levando em conta que o consumo conecta questões das nossas vidas cotidianas com questões centrais da nossa sociedade e época e se relaciona tanto com a forma com a qual devemos ou queremos viver quanto questões relativas à forma de como a sociedade é ou deveria ser organizada (Slater, 2002), ganha importância trazer para o campo novas formas de se esmiuçar esse cotidiano. Assim, parece ser adequado apontar as histórias, assim como as narrativas de vida como algo que parece compor um "arsenal" de possibilidades metodológicas disponível para o pesquisador a fim de que, combinadas com outras técnicas e metodologias, possam contribuir para o entendimento do consumo enquanto uma prática da vida cotidiana. Este olhar possibilita aos pesquisadores perceberem os consumidores de forma peculiar. Ao perceber a pertinência de suas narrativas e histórias, é possível conhecer os diferentes percursos e peculiaridades, vínculos, implicações e pertinências. Ou seja, o uso de narrativas é uma forma de recolocar o indivíduo no social e na história (Bragança, 2010). Vale lembrar que, levando em conta que toda atividade humana envolve o uso da linguagem (Galvão, 2005) e que as pessoas são contadoras de histórias, pode-se afirmar que o material oriundo das narrativas compõe um material interessante para a investigação científica (Zacarelli \& Godoy, 2013).

Alguns dos motivos que justificam a condução do presente trabalho são os seguintes. Em primeiro lugar, não é escusado apontar a pouca utilização das técnicas de narrativas no campo da pesquisa do consumidor. Em segundo lugar, vale enfatizar que a literatura atinente à pesquisa qualitativa em marketing explana superficialmente essas metodologias e pouco propõem a aproximação entre elas. Em terceiro lugar, a articulação entre os métodos de análise de narrativas e o uso de histórias parece estar alinhada a uma perspectiva que vem crescendo nos últimos anos, na qual se entende o consumo como uma construção social, fruto de uma interação entre os indivíduos no seu cotidiano. Por fim, este trabalho pode servir de ponto de partida para "convidar" outros leitores e pesquisadores a envidarem esforços no sentido de também buscarem formas de construir outras "pontes" entre diferentes campos do conhecimento. Ou seja, o texto, em forma de ensaio, assume o papel de instigar os leitores no sentido de orientá-los para reflexões acerca das possibilidades de pesquisa articulando os temas tratados (Meneghetti, 2011).

0 trabalho foi organizado da seguinte forma: inicialmente elaborou-se uma seção com o propósito de discutir o consumo com vistas a defender a posição de que se trata de um campo complexo, com diversas abordagens e possibilidades de entendimento. 0 foco recai no consumo entendido em uma perspectiva social e culturalmente construída. A seção seguinte foi incluída visando contemplar as discussões acerca da análise das narrativas, bem como da utilização de histórias com ênfase em suas definições, sua evolução em diferentes áreas e seus usos nos estudos de consumo. A seção ainda apresentou superficialmente as fases de coleta e análise de um trabalho baseado em análises narrativas. 0 ponto central do ensaio está na seção na qual se "coloca para conversar" o consumo com a proposta da análise de narrativas. Por fim, buscou-se tecer comentários de cunho conclusivo acerca de toda a discussão conduzida.

\section{REFERENCIAL TEÓRICO}

\section{$O$ consumo: um campo com diversas abordagens}

De início, é importante levar em conta que o consumo, enquanto fenômeno social, foi relegado a uma posição periférica nas Ciências Sociais até bem pouco tempo atrás (Duarte, 2010), embora seja 
possível encontrar campos no âmbito das Ciências Sociais que busquem apresentar contribuições para o fenômeno do consumo, tais como a Sociologia do Consumo (Campbell, 1995); Economia Política (Fine, 1995); Estudos Históricos (Glennie, 1995); Estudos de Mídia (Morley, 1995). Essa aparente negligência ocorreu, na visão de Rocha (2002), pelo fato de se priorizar as questões ligadas à produção, consideradas nobres e valorosas, enquanto o consumo tende a ser entendido como algo superficial e fútil, ao mesmo tempo em que é visto como inconsequente e falso.

Toda a discussão do conceito de consumo, adotado para esse texto, se adere muito à abordagem antropológica, uma vez que entendemos que consumir na sociedade atual parece estar muito voltado para questões relacionadas à forma com a qual devemos ou queremos viver ou ainda à forma de como a sociedade é ou deveria ser organizada (Slater, 2002). No entanto, não podemos deixar de mencionar que o interesse do campo da Antropologia para questões voltadas para o consumo é relativamente recente, iniciando-se no início dos anos 1980. Para Duarte (2010), essa negligência histórica tem origem em duas questões. A primeira delas tem a ver com a opção estruturante da Antropologia pelas sociedades pré-industriais. Ainda que a relação com os objetos seja algo verificado desde o nascimento das civilizações, o consumo, enquanto fenômeno contemporâneo, foi deixado de lado pelos antropólogos. A segunda questão está relacionada à forte influência do modelo marxista, cujos efeitos são sentidos na atenção sobre a produção (categoria fundamental de Marx) e o trabalho em detrimento do consumo.

Desjeux (2011) ainda traz como contribuição a questão de que as sociedades contemporâneas mantêm com o consumo uma relação ambivalente. Ao mesmo tempo em que é percebido como fonte de desejo e realização é também visto como causa de alienação, de desperdício, de perda de valores e de dissolução da cultura. Além de ter sido historicamente um tema pouco debatido nas Ciências Sociais, sua conceituação também parece ser alvo de discussão. A etimologia da palavra consumo, de acordo com Barbosa e Campbell (2006) engloba uma expressiva ambiguidade. Se levarmos em conta o termo derivado do latim consumere significa "usar tudo", "esgotar" e "destruir". Já o termo inglês consummation significa "somar", "adicionar". Vale afirmar que no Brasil o significado do termo consumo ficou mais próximo da primeira dimensão, que tem sentido negativo.

Do ponto de vista conceitual e para fins desse ensaio, os conceitos de consumo têm fortes conotações culturais e simbólicas. Uma das definições escolhidas, por ter aderência à proposta deste texto, é a de McCracken (2003). Ele apresenta o consumo como sendo "moldado, dirigido e constrangido em todos os seus aspectos por considerações culturais" (McCracken, 2003, p. 11). Para o autor, nas sociedades desenvolvidas ocidentais a cultura é profundamente ligada ao consumo. Sendo assim, os bens são os instrumentos principais de manutenção dessas sociedades. Essa relação, entretanto, demorou a ser percebida pelas ciências sociais e ainda há falhas na percepção do consumo como um fenômeno totalmente cultural (McCracken, 2003).

De importância também é a definição de Desjeux (2011), cujas contribuições tendem a confirmar que o consumo aparece como uma importante "lente" para entender a vida cotidiana, as construções identitárias, as questões políticas, os modos de vida, além de dar subsídios interessantes para se identificar estratificações sociais e elementos da globalização. 0 consumo também pode ser visto como um processo social que diz respeito a múltiplas formas de provisão de bens e serviços e a diferentes formas de acesso a esses mesmos bens e serviços. Ao mesmo tempo, pode ser encarado como um mecanismo social entendido pelas ciências sociais como produtor de sentido e de identidades. $\mathrm{Ou}$, ainda, como uma estratégia utilizada no dia a dia pelos mais diferentes grupos sociais para definir diversas situações em termos de direitos, estilos de vida e identidades ou como uma categoria central na definição da sociedade contemporânea (Barbosa \& Campbell, 2006).

Complementarmente, Rocha (2002) apresenta o consumo como parte fundamental de nossas vidas. Dessa forma, o estudo do consumo é um caminho privilegiado para entender a sociedade contemporânea. Veblen, citado por Rocha (2002), aponta a comunicação como lugar central do consumo. Os produtos e os serviços falam por nós e sobre nós. As roupas explicam a personalidade, o mobiliário explica a casa e todos os produtos expressam sentimentos, desejos ou momentos em nossas vidas: "se o sapato combina com a bolsa, a calça pode combinar com o estado de espírito e o terno com a posição social" (Rocha, 2002). 0 autor ainda apresenta o consumo, em primeiro lugar, como um sistema de significação e a principal necessidade social que supre é a necessidade simbólica. Em 
segundo, o consumo é como um código e por meio dele são traduzidas muitas das nossas relações sociais e elaboradas muitas das nossas experiências de subjetividade. Em terceiro, este código, ao traduzir sentimentos e relações sociais, forma um sistema de classificação de coisas de pessoas, produtos e serviços, indivíduos e grupos (Rocha, 2002). Deve-se ressaltar que essa visão do consumo como eminentemente cultural e simbólico só começou a ser delineada a partir dos anos 1970 com a publicação do livro de Mary Douglas e Baron Isherwood intitulado "O mundo dos bens" e com a publicação da obra La distinction de Pierre Bourdieu e somente fincou raízes na década de 1980, quando outros trabalhos importantes para o campo foram publicados.

Ao mesmo tempo, na perspectiva da antropologia do consumo, o consumidor é inserido em um nexo complexo e relacional, de forma simbolicamente informada e socialmente situada, permitindolhe construir sua racionalidade sobre essa lógica simbólica para ler a realidade. 0 enfoque da antropologia do consumo se torna fundamental para compreender essa racionalidade e as formas pelas quais os consumidores criam novos sentidos para os objetos, produtos e serviços (Migueles, 2007).

Frente a todas essas considerações, a ênfase da discussão parece recair sobre a ideia de o consumo faz parte da vida ordinária de cada um, enfim, da vida "vivida" por cada um no seu cotidiano. Ou seja, as ações cotidianas, entendidas aqui como um vasto espectro de processos conscientes e inconscientes, compreendem desde tarefas simples, como amarrar um cadarço de sapato, abrir portas e procurar roupas em uma loja, até tarefas mais complexas, como dirigir um veículo ou namorar. Em termos de consumo, é agora óbvio que um grande número de processos conscientes e inconscientes tomam lugar naquilo que foi previamente considerado uma atividade banal ou rotineira (Paterson, 2006).

\section{Histórias e Narrativas: algumas considerações}

Para se entender como a análise de narrativas adere à discussão desse artigo, é importante levar em conta que toda atividade humana envolve o uso da linguagem que pode se concretizar por meio de textos orais ou escritos (Galvão, 2005). De interesse para essa discussão é a posição defendida por Bruner (1991) ao enfatizar que organizamos nossa experiência diária e nossa memória de acontecimento principalmente em forma de narrativas - histórias, desculpas, mitos e razões para fazer e não fazer algo. Essa mudança de perspectiva torna as narrativas um movimento capaz de revelar ou sugerir soluções para problemas que tipicamente não vinham sendo reconhecidos pelos métodos convencionais de pesquisa. Esses problemas parecem ter como características marcantes a natureza ambígua da verdade, o componente metafórico da linguagem ao comunicar a realidade, a temporalidade da interpretação dos seres humanos sobre suas vidas, as restrições culturais sociohistóricas que os indivíduos têm para transmitir informações sobre si mesmos, assim como o projeto de produzir algo científico por meio de material biográfico (Sandelowski, 1991).

Assim, a narrativa é uma forma convencional, transmitida culturalmente e limitada por questões relacionadas ao contexto social. No mesmo sentido, as narrativas podem ser entendidas como uma versão da realidade. Versão essa que tende a ser mais aceita por convenção e necessidade do que por verificação empírica e requisitos lógicos (Bruner, 1991). Dessa forma, o termo "narrativas" pode assumir diferentes significados dependendo do ponto de vista analisado. Tal como enfatizado por Riessman (2008), nas ciências sociais, as narrativas se referem a textos que podem se originar em histórias contadas por participantes de pesquisa, em interpretações desenvolvidas por um pesquisador baseadas em entrevistas e observações e mesmo em narrativas de um leitor após se engajar com as narrativas de participante e de investigador.

Uma vez que as narrativas são compostas de histórias ou fábulas, compreendendo ações, acontecimentos, sujeitos, discursos entre outros, vale levar em consideração que os mesmos elementos de uma história podem ser diferentemente contados, resultando em uma variedade de narrativas (Sandelowski, 1991). Para Pentland (1999), os dados narrativos têm propriedades que fornecem a base para muitos tipos de teorias. A primeira delas tem a ver com a sequência no tempo, ou seja, uma narrativa deve incluir um início, meio e fim, embora algumas histórias fragmentadas podem ainda representar tempo e sequência. Outra propriedade é a presença de um ator ou atores focais. 
Nesse sentido, narrativas são sempre sobre alguma coisa ou alguém. Existe sempre um protagonista e, frequentemente, um antagonista. É característica de uma narrativa a identificação de uma voz narrativa que reflete um específico ponto de vista. Outra propriedade tem a ver com um quadro de avaliação de referência. Isso se torna importante visto que as narrativas carregam valores e significados culturais que englobam padrões em que ações dos sujeitos podem ser julgados. Por fim, uma propriedade importante é a necessidade de outros indicadores de conteúdo e de contextos.

A análise de narrativas, portanto, refere-se a uma família de métodos para interpretar textos que têm em comum a forma de histórias. É importante frisar que o analista de narrativas deve buscar continuamente interrogar tanto as intenções como a linguagem, ou seja, como e porque os incidentes são contados, não simplesmente o conteúdo ao qual a linguagem se refere (Riessman, 2008). A análise de narrativas no campo dos estudos de organizações é relativamente recente, visto que os primeiros estudos são datados dos anos 1970. Porém, analisar as narrativas somente encontrou maior aderência no campo das organizações após os anos 1980 quando houve um significativo crescimento de pesquisas envolvendo o simbolismo das experiências vivenciadas pelos indivíduos no interior das organizações (Rhodes \& Brown (2005).

Já no campo do marketing, mais especificamente nos estudos do consumo, a utilização das narrativas e histórias é bem mais modesta e se inicia a partir dos anos 2000. São poucos os trabalhos que lançam mão dessas metodologias, tendo em vista a característica da área que é ser conservadora e ainda manter uma forte relação com técnicas quantitativas de pesquisa (Belk, 1995; Levy, 2006). Alguns exemplos da utilização dos métodos narrativos em trabalhos envolvendo o consumo são os estudos de Moisander and Pesonen (2002), Tovey and Manson (2004), Deighton and Narayandas (2004), Escalas (2004), Baker (2006), Hopkinson and Hogg (2006) e Kozinets (2008).

Cabe ressaltar ainda que as narrativas parecem encontrar maior eco no campo quando a perspectiva do consumo passou a dar lugar a uma vertente mais ligada ao social e culturalmente construído. Não menos importante é a constatação de que metodologicamente, a adesão aos métodos narrativos aos estudos do consumo tem origem na fragmentação teórica, típica de diversos campos de estudos na atualidade, na qual é preponderante a centralidade do discurso, ou seja, a linguagem é constitutiva da realidade. A próxima seção joga luz sobre as questões metodológicas relativas à análise de narrativas.

\section{ANÁLISE DE NARRATIVAS: CONSIDERAÇÕES METODOLÓGICAS}

Esse tópico do artigo se dedica a tecer comentários acerca das questões metodológicas da análise de narrativas quando articulada aos estudos de consumo. Um dos pontos interessantes está relacionado ao papel do pesquisador no processo de pesquisa. Riessman (2008) defende que o pesquisador deve assumir uma presença ativa no texto, uma vez que a narrativa é coproduzida por ele juntamente com os entrevistados. Devido à questão da amplitude que o campo da análise das narrativas vem assumindo nas últimas décadas, é importante levar em consideração que existem inúmeros métodos que podem ser utilizados em conjunto. Entre eles, Stanfield (1987) elenca a história oral, a biografia, a biografia fictícia e a autobiografia, sem falar das entrevistas em profundidade. Fica evidente que a escolha da ferramenta está relacionada com a perspectiva que se dá ao trabalho, bem como às características de cada pesquisa empírica. Percebe-se, contudo, que todos esses métodos têm pouca utilização em pesquisas do consumidor.

Operacionalmente, Gibbs (2009), com base em outros autores, propõe uma sequência de elementos narrativos que compõem uma estrutura de análise: resumo, orientação, ação complicadora, avaliação, resolução e coda. A figura 1 apresenta cada um desses elementos e suas respectivas perguntas orientadoras.

\begin{tabular}{|l|l|l|}
\hline \multicolumn{1}{|c|}{ ELEMENTO } & \multicolumn{1}{|c|}{ CARACTERÍ́sTICA } & \multicolumn{1}{c|}{ PERGUNTAS } \\
\hline Resumo & $\begin{array}{l}\text { Marca o início da narrativa, contendo } \\
\text { uma proposição }\end{array}$ & De que se trata? \\
\hline Orientação & $\begin{array}{l}\text { Indica o lugar, o tempo a situação e os } \\
\text { participantes }\end{array}$ & O que, onde, quando? \\
\hline
\end{tabular}




\begin{tabular}{|l|l|l|}
\hline Ação complicadora & $\begin{array}{l}\text { Desenvolve a sequência de fatos. Tem } \\
\text { como foco o relato dos eventos ocorridos }\end{array}$ & E depois, o que aconteceu? \\
\hline Avaliação & Discute o significado o sentido da ação & E então? \\
\hline Resolução & $\begin{array}{l}\text { Relata como foi resolvida a ação } \\
\text { complicadora }\end{array}$ & O que aconteceu afinal? \\
\hline Coda & $\begin{array}{l}\text { Determina o fim da narrativa, com a } \\
\text { possibilidade de voltar ao presente }\end{array}$ & Como terminou? \\
\hline
\end{tabular}

Fonte: Adaptado de Gibbs (2009)

Figura 1 - Elementos narrativos

No sentido de também contribuir na operacionalização dos métodos narrativos, Saraiva (2007) apresenta, sem a intenção de propor uma receita, alguns passos que podem ser usados na confecção de pesquisas baseadas em métodos narrativos. A figura 2 explana cada uma das etapas propostas.

\begin{tabular}{|c|c|}
\hline ETAPAS & CONSIDERAÇÕES \\
\hline $\begin{array}{l}\text { Planejamento } \\
\text { Organização }\end{array}$ & $\begin{array}{l}\text { Como qualquer pesquisa qualitativa, o planejamento não pode ser } \\
\text { considerado a principal fase. Será o processo de interação com a narrativa } \\
\text { que moldará a pesquisa. A problemática da pesquisa é central, por isso, o } \\
\text { foco inicial deve as narrativas que circundem o tema, de forma a ampliar o } \\
\text { nível de compreensão daquele fenômeno. }\end{array}$ \\
\hline $\begin{array}{l}\text { Seleção dos Sujeitos da } \\
\text { Pesquisa }\end{array}$ & $\begin{array}{l}\text { É necessário que o pesquisador se certifique de que os sujeitos de quem se } \\
\text { pretende ouvir as narrativas são detentores das experiências necessárias a } \\
\text { serem narradas. }\end{array}$ \\
\hline Coleta de Narrativas & $\begin{array}{l}\text { Para se chegar a um volume de informações adequado para a construção de } \\
\text { uma narrativa é fundamental que vários encontros sejam agendados para } \\
\text { que o entrevistado tenha condições de resgatar memórias e, a partir daí, } \\
\text { construir sua narrativa. }\end{array}$ \\
\hline Análise das Narrativas & $\begin{array}{l}\text { Quatro possibilidades de leitura são possíveis. A primeira delas é a leitura } \\
\text { holística de conteúdo, a qual leva em consideração a história inteira e seu } \\
\text { conteúdo. Nesse sentido, a narrativa ganha uma conotação mais universal. A } \\
\text { segunda possibilidade é a leitura holística da forma. Essa também enfoca a } \\
\text { história como um todo, mas trata de seus aspectos formais mais do que no } \\
\text { seu conteúdo. Outra é a leitura categorial de conteúdo trata do conteúdo das } \\
\text { narrativas em partes separadas da história sem considerar o contexto } \\
\text { completo. Por fim, a leitura categorial de forma considera aspectos formais } \\
\text { de seções separadas ou categorias de uma história de vida tais como } \\
\text { "contexto", "os protagonistas", etc. }\end{array}$ \\
\hline Validação do Estudo & $\begin{array}{l}\text { Ainda que não esteja disponível um aparato prévio como o existente em } \\
\text { estudos quantitativos, na análise de narrativas é importante lançar mão de } \\
\text { critérios como os de validade, da qualidade e da representatividade. }\end{array}$ \\
\hline
\end{tabular}

Fonte: Adaptado de Saraiva (2007)

Figura 2 - Etapas de operacionalização de uma pesquisa baseada em métodos narrativos

Vale comentar que os estudos envolvendo análise de narrativas tendem a ser criticados por priorizar as descrições e as interpretações em detrimento de análises teóricas (Sandelowski, 1991). Nesse contexto, parecem ganhar vulto as considerações levantadas por Sandelowski (1991) no tocante a relação entre narrativas e ficções. Para essa autora, as ficções não são opostas à verdade no contexto das narrativas, mas elas são verdades dentro das histórias que as contém. Frente a todas essas discussões parece fazer sentido iniciar a discussão na qual se confronta a análise de histórias e narrativas com as questões envolvendo o consumo como prática cotidiana na tentativa de se verificar o quanto é viável haver a aproximação entre os campos. 


\section{A Análise de Histórias e Narrativas e o Consumo: uma aproximação viável}

Essa seção do trabalho tem o intuito de confrontar a discussão presente na literatura pesquisada atinente ao tema consumo em uma perspectiva social e culturalmente construída com o campo metodológico da análise de narrativas a fim de discutir se há aderência entre ambas, bem como identificar pontos de concordância e de discordância. Em primeiro lugar, vale considerar que uma premissa básica no que concerne à pesquisa na área de marketing e especialmente na pesquisa envolvendo consumo, para tentar entender a natureza dos desejos dos consumidores, os métodos tradicionais de pesquisa podem ser, não raramente, bastante limitados. Eles não são adequados para extrair fantasias do consumidor. Complementarmente, é possível ressaltar ainda a dificuldade em pesquisas na área mercadológica em obter uma resposta adequada para questões do tipo "por quê". Nesse contexto, surgem as histórias e as narrativas para tentar explicar motivações, atitudes e valores que moldam o comportamento e o fluxo das ações humanas.

Para Sanderlowski (1991), as narrativas são compostas de histórias ou fábulas, compreendendo fatos, acontecimentos, sujeitos, lugares, discursos. Tanto as histórias como as narrativas parecem ter aderência à noção de que a linguagem é algo fundamental para constituição da realidade, visto que os objetos podem ser compreendidos como construções discursivas. Ademais, histórias podem ser lidas tanto como ilustrações da teoria e ainda descobertas para a teoria (Deighton $\&$ Narayandas, 2004). Esses pontos parecem fazer sentido quando se pensa em consumo, uma vez que em boa parte das ações de consumo são permeadas por fatos, acontecimentos, sujeitos, lugares, discursos. Em suma, nesse ponto, parece haver plena aderência entre eles.

Em segundo lugar, as narrativas partem do entendimento de que existem múltiplos caminhos por meio dos quais uma mesma situação pode ser contada, o que força à noção de que os atos de consumo podem (e devem) ser entendidos a partir de atividades discursivas em um contexto marcado por interações sociais. Em outras palavras, todas as formas de consumo são culturalmente específicas. Isso quer dizer que elas são articuladas conforme ou em relação a formas de vida significativas e específicas que podem ser "lidas" por meio das narrativas.

No mesmo sentido, levando em conta que compreender o consumo enquanto uma prática que ocorre em um processo de "escrita e leitura", a adoção das narrativas como recurso metodológico para o entendimento dessa realidade parece ser a trilha a ser desbravadas pelos pesquisadores. Não se pode esquecer ainda que o consumidor, em suas atividades cotidianas, (re)interpretam, (re)aprendem, (re)experimentam, (re)constroem suas escolhas e negociação os significados continuamente, o que faz da análise das narrativas algo rico e adequado para se pesquisar essas questões.

Ainda com relação a esse ponto, é interessante abordar que levando em conta as diversas alternativas para se entender o debate entre "agência" e "estrutura" no campo do consumo, a análise de narrativas pode oferecer subsídios pertinentes para se investigar questões diversas. No mesmo sentido, a análise de narrativas também parece ter um papel interessante no desafio de se trabalhar com as contradições, paradoxos, ambiguidades e incoerências tão marcantes nos atos de consumo entendido como prática cotidiana.

Do ponto de vista ontológico e epistemológico, pode-se assumir que o consumo na perspectiva social e culturalmente construída no dia a dia encontra amparo nas principais vertentes da análise de narrativas, visto que ambas convergem para posições mais voltadas ao subjetivismo, baseadas no nominalismo e no anti-positivismo. Quanto ao aspecto metodológico, parece haver uma aproximação entre narrativas e consumo pelo fato de ambas ter uma perspectiva ideográfica. Além disso, na análise de narrativas torna-se essencial que o pesquisador se apresente no texto, assuma a responsabilidade de co-produtor dos resultados, algo que também é fundamental quando se investigam as questões de consumo entendidas como ação cotidiana.

Na seara de conversações metodológicas, cabe explorar a inserção de outros métodos de pesquisas que poderiam ser úteis para facilitar a articulação entre o consumo e a análise de narrativas. Como exposto anteriormente, os métodos narrativos são vários incluindo a autobiografia, a história oral, a entrevista em profundidade, a biografia e a biografia fictícia entre outras. Outras metodologias de base qualitativas podem se juntar a essas a fim de se compor um arcabouço metodológico que 
possa dar conta da complexidade dos fenômenos sob investigação. Deve-se ressaltar que essa iniciativa é algo que precisa ser levado em consideração pelos pesquisadores do consumo.

Nesse sentido, a etnografia pode oferecer um arsenal interessante de técnicas para fomentar a construção de narrativas visto que consiste no processo de observar, participar e conversar com o "nativo" em suas condições reais de existência, tentando entender e mapear a completude de sua vida, os diferentes princípios, as "lógicas" e os significados por meio dos quais as pessoas atribuem sentido e organizam a "realidade" em que vivem (Barbosa, 2003). O trabalho de campo, que normalmente envolve uma combinação de observação direta e entrevistas em profundidade, permite que o "ponto de vista nativo" sobre as experiências e práticas cotidianas seja enriquecido por informação visual e emocional - ethos - que permeia a situação (Barbosa, 2003). Isso parece ter grande aderência às narrativas de práticas de consumo.

Outra metodologia importante, ainda que pouco usual nos estudos de consumo, é a fenomenologia visto que ela contribuiria com a busca do entendimento das experiências a partir do ponto de vista dos consumidores. Complementarmente, a fenomenologia interpretativa se propõe a trazer à tona significados imbricados nas práticas comuns da vida cotidiana (Lopez \& Willis, 2004). Significados esses que nem sempre são evidentes para os praticantes, e que, portanto, nem sempre podem ser conscientemente relatados por eles, mas que poderiam ser apreendidos a partir das suas narrativas sobre a sua forma de "ser no mundo", sobre o que elas experimentam diariamente no "seu mundo". A análise de discurso em suas várias vertentes e escolas (francesa, crítica, Foucaultiana, Bakthiniana entre outras) desponta nesse contexto como um aporte teórico e metodológico não somente interessante, mas necessária para mostrar a forma com que as ideias produzidas socialmente contribuem para a construção da realidade. Considerando nossa sociedade atual rotulada como "de consumo" que emergiu a partir de uma série de mudanças políticas, econômicas e sociais que operou por séculos, parece ser plausível considerar que as histórias e narrativas podem conter elementos que contribuem para construir identidades, formas de sociabilidade e construção de "visões de mundo".

Sem a pretensão de ser exaustivo, a lista de possibilidades tende a elencar outros métodos e técnicas, que conjugados, sirvam de base para compor arcabouços metodológicos que possam contribuir tanto para o campo do consumo como para a ampliação do alcance da análise das narrativas. Entre essas possibilidades podem ser apontadas as técnicas projetivas, a história oral, o uso de metáforas, a implementação de grupos de foco e o aporte da técnica de foto e vídeo elicitação. Nesse ponto, parece fazer sentido caminhar para as considerações finais do trabalho com o intuito de se apresentar apontamentos conclusivos acerca de todas as discussões empreendidas no ensaio.

\section{CONSIDERAÇÕES FINAIS}

De início, cabe concluir que os pontos de contato visíveis que relacionam os processos intersubjetivos baseados nas vivências compartilhadas pelas pessoas, que, consensualmente dão sentido ao mundo que as rodeiam, são comuns tanto à tradição da Análise de Narrativas quanto à tradição dos estudos em consumo na perspectiva adotada neste ensaio. A ideia de que as narrativas envolvem a natureza ambígua da verdade, bem como a natureza metafórica da linguagem na comunicação de uma realidade, supostamente objetiva, além do caráter inerentemente contraditório de discutir algo do ponto de vista narrativo, encontra eco na perspectiva do consumo enquanto prática social cotidiana.

O ensaio cumpre seu papel ao entregar uma contribuição que aponta os vínculos entre as metodologias baseadas em narrativas e histórias de vida para os estudos de consumo por meio das vivências compartilhadas pelos sujeitos, alinhados ao seu cotidiano e experiências particulares. 0 texto apresenta ainda as possibilidades de conversação entre metodologias, o que parece auxiliar no avanço do campo, ainda que seja necessária a condução de outros trabalhos para aprofundar pontos que ficaram obscuros na discussão.

Dessa forma, tentando responder à pergunta presente no subtítulo do trabalho, é adequado concluir que a Análise de Narrativas oferece possibilidades interessantes para os pesquisadores do consumo. Nesse ponto, cabem algumas sugestões para a continuação do estudo. Fica evidente que as 
questões de interlocução entre narrativas e estudos do consumo podem (e devem) continuar com a incorporação de novas discussões e perspectivas.

Dito de outra forma, é essencial investir em promover a aproximação de outros pontos de vista, perspectivas teóricas e metodológicas. Por outro lado, torna-se premente colocar em prova o que se conclui aqui, por meio da condução de estudos empíricos envolvendo as duas abordagens, narrativas nos estudos de consumo a fim de se verificar empiricamente, a aproximação pertinente para ambas as partes. Com o intuito de contribuir na proposição de uma agenda de pesquisa, fica fácil perceber que o rol de possibilidades é bastante extenso, tendo em vista a amplitude que a perspectiva do consumo em uma vertente social e culturalmente construída pode oferecer.

As propostas podem caminhar no sentido não somente de questões simbólicas do cotidiano dos consumidores em diferentes situações ou experiências de consumo, mas também em discussões relacionadas às idiossincrasias dos consumidores originadas das mais diversas classes sociais, regiões, idade, grupos sociais e "tribos" dos quais eles fazem parte. Nesse ponto, cabem algumas sugestões para a continuação do estudo. Fica evidente que as questões de interlocução entre narrativas e estudos do consumo podem (e devem) continuar com a incorporação de novas discussões e perspectivas. Dito de outra forma, é essencial investir em promover a aproximação de outros pontos de vista, perspectivas teóricas e metodológicas.

Com o intuito de contribuir na proposição de uma agenda de pesquisa, fica fácil perceber que o rol de possibilidades é bastante extenso, tendo em vista a amplitude que a perspectiva do consumo pode oferecer. Sugere-se, assim, um conjunto de investigações que busque entender a relação dos consumidores com a alimentação, com a materialidade de objetos diversos, das relações que podem ser criadas com produtos e serviços de tecnologia, com atividades de lazer, e outras esferas, são exemplos da pujança desse campo. A contínua (re)socialização dos indivíduos para o consumo por meio de vários eventos do cotidiano é outra temática que merece atenção dos pesquisadores.

\section{Referências}

Baker, S. M. (2006). Consumer normalcy: Understanding the value of shopping through narratives of consumers with visual impairments. Journal of Retailing, 82(1), 37-50.

Barbosa, L. (2003). Marketing Etnográfico: colocando a Etnografia em seu Devido Lugar. Revista de Administração de Empresas, 43(3), p.100-105.

Barbosa, L., \& Campbell, C. O (2006). Estudo do Consumo nas Ciências Sociais Contemporâneas. In: Barbosa, L. \& Campbell, C. (org.). Cultura, Consumo e Identidade. Rio de Janeiro: FGV.

Belk, R. W. (1995). Studies in the New Consumer Behaviour. In: Miller, D. Acknowledging Consumption. New York: Routledge.

Bragança, E. M. (2010, setembro). História de Vida e Consumo - Uma Proposição Metodológica para a Pesquisa do Comportamento do Consumidor. Anais do XXXIV EnANPAD, Rio de Janeiro, Brasil.

Bruner, J. (1991). The Narrative Construction of Reality. Critical Inquiry, 18(1), 1-21.

Campbell, C. (1995). The Sociology of Consumption. In: Miller, D. Acknowledging Consumption. New York: Routledge.

Deighton, J., \& Narayandas, D. (2004). 'Stories and theories', an invited commentary on 'Evolving to a new dominant logic for marketing', Journal of Marketing, 68(1), 19-20.

Desjeux, D. (2011). O consumo: abordagens em Ciências Sociais. Maceió-AL: EDUFAL.

Duarte, A. (2010). A Antropologia e o Estudo do Consumo: revisão crítica das suas relações e possibilidades. Etnográfica, 14(2), 363-393.

Escalas, J. E. (2004). Narrative Processing: Building Consumer Connections to Brands. Journal of Consumer Psychology, 14(1-2), 168-180.

Fine, B. (1995). From Political Economy to Consumption. In: Miller, D. Acknowledging Consumption. New York: Routledge.

Galvão, C. (2005). Narrativas em Educação. Ciência \& Educação, 11(2), 327-45.

Gibbs, G. (2009). Análise de Dados Qualitativos. Porto Alegre: Artmed. 
Glennie, P. (1995). Consumption within Historial Studies. In: Miller, D. Acknowledging Consumption. New York: Routledge.

Hopkinson, G. C., \& Hogg, M. K. (2006). Stories: how they are used and produced in market(ing) research. In: Belk, R. W. Handbook of Qualitative Research Methods in Marketing. Northampton: Edward Elgar Publishing.

Kozinets, R. (2008). Technology/Ideology: How Ideological Fields Influence Consumers' Technology Narratives. Journal of Consumer Research, 34(6), 865-881.

Levy, S. (2006). History of Qualitative Methods in Marketing. In: Belk, R. W. Handbook of Qualitative Research Methods in Marketing. Northampton: Edward Elgar Publishing.

Lima, D. N. (2011). Consumo: uma perspectiva antropológica. Petrópolis-RJ: Vozes.

Lopez, K. A., \& Willis, D. G. (2004). Descriptive Versus Interpretive Phenomenology: Their Contributions to Nursing Knowledge. Qualitative Health Research, 14(5), 726-735.

Macinnis, D. J., \& Folkes, V. S. (2010). The Disciplinary Status of Consumer Behavior: A Sociology of Science Perspective on Key Controversies. Journal of Consumer Research, 36(6), 899-914.

McCracken, G. (2003). Cultura e Consumo: novas abordagens ao caráter simbólico dos bens e das atividades de consumo. Rio de Janeiro: Mauad.

Meneghetti, F. H. (2011). O que é um Ensaio-Teórico? Revista de Administração Contemporânea, 15(2), 320-332.

Migueles, C. (2007). (Org.) Antropologia do Consumo: Casos brasileiros. Rio de Janeiro: Editora FGV.

Moisander, J., \& Pesonen, S. (2002). Narratives of sustainable ways of living: constructing the self and the other as a green consumer. Management Decision, 40(4), 329-342.

Morley, D. (1995). Theories of Consumption in Media Studies. In: MILLER, D. Acknowledging Consumption. New York: Routledge.

Paterson, M. (2006). Consumption and Everyday Life. London: Routledge.

Pentland, B. T. (1999). Building Process Theory with Narrative: from description to explanation. Academy of Management Review, 24(4), 711-24.

Rhodes, C. \& Brown, A. D. (2005). Narrative, Organizations and Research. International Journal of Management Review, 7(3), 167-188.

Riessman, C. (2008). Narrative Methods for the Human Sciences. London: Sage.

Rocha, E. (2002). Cenas do Consumo: Notas, Ideias, Reflexões. Revista Semear, 06.

Sandelowski, M. (1991) Telling Stories: Narratives Approaches in Qualitative Research. Journal of Nursing Scholarship, 23(3).

Saraiva, L. A. S. (2007). Métodos Narrativos de Pesquisa: Uma aproximação. Gestão.org, 5(2), 119-134.

Slater, D. (2002). Cultura do Consumo e Modernidade. São Paulo: Nobel.

Stanfield, J. H. (1987). Life History Analysis and Racial Stratifications Research. American Behavioral Scientist, 30(4), 429-440.

Zaccarelli, L. M., \& Godoy, A. S. (2013). "Deixa eu te contar uma coisa...": possibilidades do uso de narrativas e sua análise nas pesquisas em organizações. Revista Gestão Organizacional, 6(3), 2536. 